\title{
Electrochemical Synthesis of Titanium Nano Particles at Carbon Paste Electrodes and Its Applications as an Electrochemical Sensor for the Determination of Acetaminophen in Paracetamol Tablets
}

\author{
K. J. Gururaj, B. E. Kumara Swamy* \\ Department of P.G. Studies and Research in Industrial Chemistry, Kuvempu University, Shimoga, India. \\ Email: *utpalchemiitkgp@yahoo.com
}

Received October $1^{\text {st }}, 2013$; revised November $6^{\text {th }}, 2013$; accepted November $13^{\text {th }}, 2013$

Copyright (C) 2013 K. J. Gururaj, B. E. Kumara Swamy. This is an open access article distributed under the Creative Commons Attribution License, which permits unrestricted use, distribution, and reproduction in any medium, provided the original work is properly cited.

\begin{abstract}
Titania nano particles were synthesized at carbon paste electrode by cyclic voltammetry and then it was employed for the determination of acetaminophen in phosphate buffer at $\mathrm{pH}$ 7.4. Carbon paste electrode with titania nano particle displayed excellent electrochemically catalytic activities by shifting the oxidation potential of acetaminophen towards the negative side. The mass transfer process at electrochemical interface was diffusion controlled. Electrochemical techniques such as, electrochemical impedance spectroscopy (EIS) and potentiodynamic polarization methods were used to measure the resistance of the electrodes. The resistance of the titanium electrode decreased in two orders when compared to the bare carbon paste electrode; the decrease in the resistance of the electrode and increase in the surface area of the electrode are responsible for the negative shifting of the oxidation potential of acetaminophen. The present method was applied to the determination of actetaminophen in paracetamol tablet, urine and blood sample by using standard addition method and the obtained results were satisfactory with a good recovery of $98 \%$.
\end{abstract}

Keywords: Titania Nano Particles; Electrochemical Sensor; Electrocatalysis; Cyclic Voltammetry; Electrochemical Impedance Spectroscopy

\section{Introduction}

Acetaminophen/paracetamol (ACOP) is an active ingredient of several pharmaceutical products, widely used as an analgesic [1]. Acetaminophen overdose is a frequent cause of fulminating hepatic failure in Europe and the USA [2]. However, recent studies have shown that paracetamol is associated to hepatic toxicity and renal failure despite of its apparent innocuous character [3]. Voltammetric techniques are more selective, less timeconsuming and widely used for the determination of acetaminophen [4]. Carbon paste electrode (CPE), which is made up of carbon particles and silicon oil binder, has been widely applied in the electroanalytical community due to its low cost, ease of fabrication, high sensitivity for detection and renewable surface. To further improve

${ }^{*}$ Corresponding author. the sensing properties of CPE they are modified by surfactants and nanoparticles. In this paper, a novel, simple, precise and sensitive, cyclic voltammetric method utilizing a tiatania nanoparticle modified carbon paste electrode for the detection of acetaminophen was reported. The method was applied successfully for the detection of acetaminophen in paracetamol tablets, urine and serum.

\section{Experimental Part}

\subsection{Materials}

$0.05 \mathrm{~g} \mathrm{TiO}_{2}$ dispersed in $25 \mathrm{ml}$ of dimethylformamide in (Merck made), $0.04 \mathrm{M}$ of glycine solution prepared in aqueous solution for modification of carbon electrode. ACOP was prepared $1 \times 10^{-5} \mathrm{M}$ stock solution was prepared by dissolving in distilled water solution. Phosphate buffer solution (PBS) was prepared sodium dihydrogen phosphate monohydrate and disodium hydrogen phos- 
phate. Chemicals mentioned above were all of analytical grade. The water used in the preparation of solutions was double distilled water.

\subsection{Apparatus}

The electrochemical experiments were carried out using a CHI 660C. All experiments were carried out in a conventional three-electrode system.

\subsection{Preparation of Bare Carbon Paste Electrode and Polyglycine $\mathrm{TiO}_{2}$ Carbon Paste Electrode (MCPE)}

Bare carbon paste electrode was prepared as described [5], polyglycine $\mathrm{TiO}_{2}$ modified carbon paste electrode was prepared by dispersing $\mathrm{TiO}_{2}$ solution with $0.04 \mathrm{M}$ glycine in pH7.4 PBS. Electropolymerisation was achieved by the formation of film that grew between $-0.5 \mathrm{~V}$ and $1.8 \mathrm{~V}$ at the scan rate of $50 \mathrm{mV} / \mathrm{s}$ for 10 cycles using cyclic voltammetry as shown in Figure 1(a).

\section{Results and Discussion}

\subsection{Cyclic Voltammetric Investigation of ACOP at MCPE}

The voltammetric behavior of ACOP was examined using cyclic voltammetry. Figure 1 shows typical cyclic voltammograms of $1.0 \times 10^{-5} \mathrm{M}$ of ACOP, in PBS pH 7.4 at scan rate $50 \mathrm{mV} \cdot \mathrm{s}^{-1}$ recorded at two different working electrodes BCPE (solid line) and MCPE (dashed). The MCPE shows significant increase in current (almost 9 folds) compare to BCPE and potential of

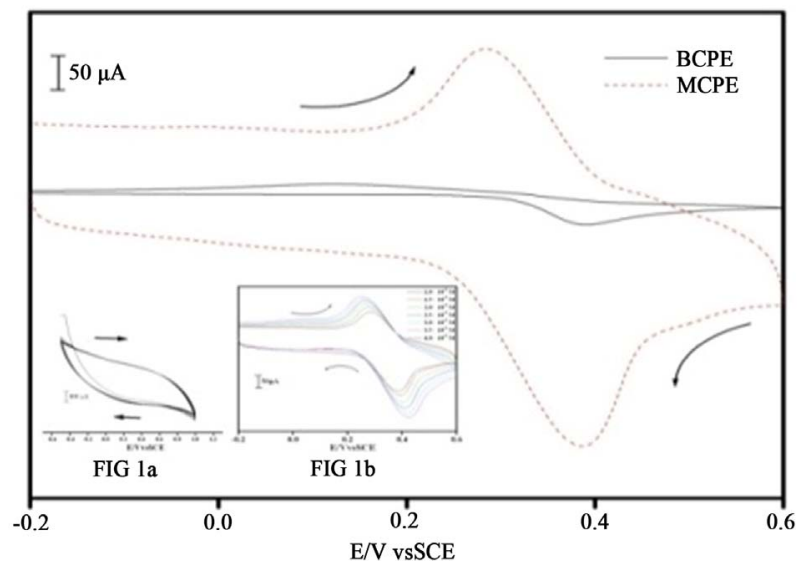

Figure 1. Cyclic voltammogram of $10 \mathrm{mM}$ acetaminophen at $\mathrm{BCPE}$ (solid line) and $\mathrm{TiO}_{2} /$ glycine $\mathrm{MCPE}$ (dotted line) in $0.1 \mathrm{M}$ PBS pH 7.4 scan rate $50 \mathrm{mV} \cdot \mathrm{s}^{-1}$ (a) Figure 1(a) Cyclic voltammogram for the electrochemical polymerisation of $\mathrm{TiO}_{2}$ dispersed glycine at carbon paste electrode (b) Figure 1(b) Cyclic voltammogram of acetaminophen at different concentration at $\mathrm{TiO}_{2}$ /glycine $\mathrm{MCPE}$ in $0.1 \mathrm{M} \mathrm{PBS}$ of $\mathrm{pH} 7$.
MCPE shifted to less positive when compare to BCPE, due to the improvement in the reversibility of the electron transfer process and improvement of surface area of the modified electrode. The MCPE resulted in an observable increase in the peak current, which indicated an improvement in the electrode kinetics and a decrease in the potential of oxidation substantially. The inset Figure 1(b) shows the effect of concentration variation of ACOP at MCPE.

\subsection{Effect of Scan Rate on the Peak Currents of ACOP}

The effect of scan rate for ACOP was studied by $\mathrm{CV}$ at MCPE (shown in Figure 2). MCPE showed increase in the redox peak current with increase in scan rate $(50$ $100 \mathrm{mV} \cdot \mathrm{s}^{-1}$ ) (Inset figure). The graph of current (Ipa) vs square root of scan rate $(v)$ was plotted. The graph obtained was good linearity between the scan rate and Ipa (Figure 3). In the range from 50 to $100 \mathrm{mV} \cdot \mathrm{s}^{-1}$ the anodic peak currents were proportional to the scan rate $(v)$. The correlation coefficient was 0.9942 , which indi- cate the electrode reaction was adsorption controlled (5).

\subsection{Electrochemical Impedance Spectroscopy}

Electrochemical impedance spectroscopy is considered to be an effective tool for investigating the property of electrode interface. Figure 3 shows the complex plane diagram (Nyquist plot, Z' versus Z"). The impedance behavior of the electrochemical impedance spectroscopy of BCPE and MCPE was studied in PBS of $\mathrm{pH}$ 7.4. The equivalent circuit used analyze the impedance behavior is shown in the inset figure. A semicircle with a large diameter is observed at the unmodified electrode, indicating the high charge resistance of $\mathrm{BCPE}(14.8 \mathrm{~K} \Omega)$ and it

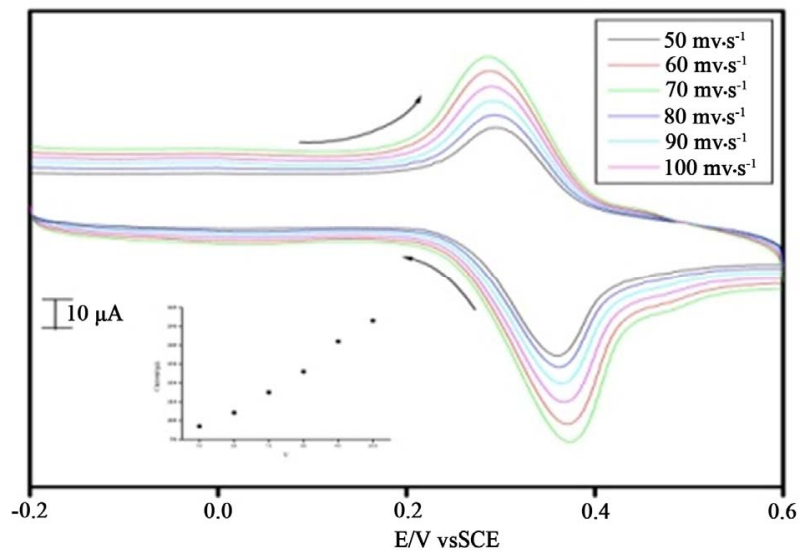

Figure 2. Cyclic voltammogram of different scan rate in the presence of $10 \mathrm{mM}$ acetaminophen in PBS at pH 7.4, scan rate $50 \mathrm{mV} \cdot \mathrm{s}^{-1} 100 \mathrm{mV} \cdot \mathrm{s}^{-1}$ inset figure $\mathrm{Graph}$ of anodic peak current $\mathrm{v} / \mathrm{s}$ scan rate. 
is difficult for the electron transfer at electrode surface. However, the diameter of semicircle diminishes significantly at MCPE. It was obvious that charge transfer resistance $(6.7 \mathrm{~K} \Omega)$ of the electrode surface decreased and the charge transfer rate sped up. Overall impedance study suggests on the surface of MCPE electron transfer is easy when compare to BCPE.

\subsection{Detection of Acetaminophen in Tablets, Urine and Serum}

In order to testify the performance of this sensor in real sample analysis, it was used to determine the content of ACOP in tablets. Then commercial pharmaceutical samples (tablets) containing ACOP was analyzed to evaluate the validity of the proposed method (results tabulated in Table 1), analysis of ACOP in urine was done by using procedure of [6] and in the same manner detection of ACOP in serum carried out (Table 2).

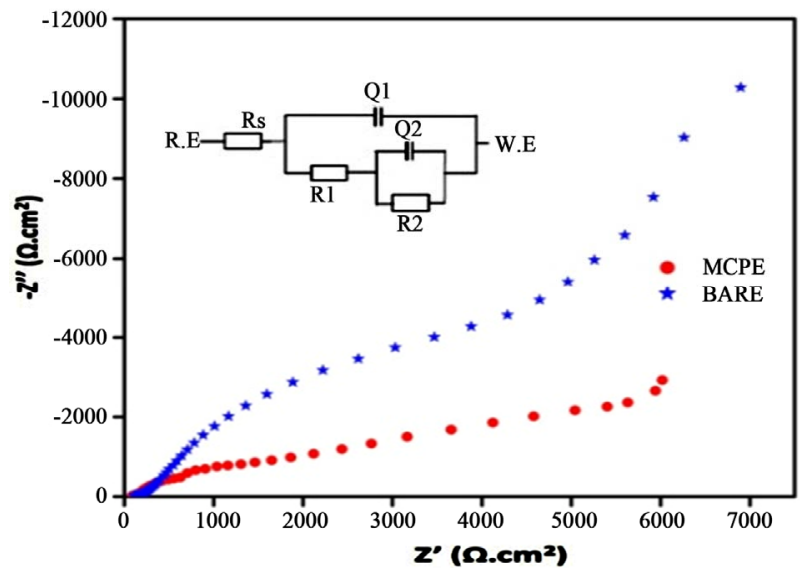

Figure 3. Electrochemical impedance spectroscopy (Nyquist plot) of $\mathrm{BCPE}$ and $\mathrm{TiO}_{2} /$ glycine $\mathrm{MCPE}$ in $\mathrm{PBS}$ at $\mathrm{pH}$ 7.4.

Table 1. Commercial pharmaceutical samples (1).

\begin{tabular}{lcccc}
\hline Formulation & Tablet taken & $\begin{array}{c}\text { Standard } \\
\text { addition }\end{array}$ & Found & Recovery \\
\hline paracetamol & $2 \mathrm{mg}$ & $2 \mathrm{mg}$ & 3.75 & $98.60 \%$ \\
\hline
\end{tabular}

Table 2. Commercial pharmaceutical samples (2).

\begin{tabular}{cccc}
\hline Sample & ACOP added (mg) & Found (mg) & Recovery \\
\hline Urine & 2 & 1.95 & $97 \%$ \\
Urine & 3 & 2.94 & $98 \%$ \\
Serum & 2 & 1.89 & $94 \%$ \\
Serum & 3 & 2.85 & $95 \%$ \\
\hline
\end{tabular}

\section{Conclusion}

The poly glycine $\mathrm{TiO}_{2}$ was synthesized, and then it was employed for detection of ACOP electrochemically in serum, tablets and urine. The study reveals that, the MCPE shows as an excellent electrochemical sensor and the same method can be applied for organic and inorganic neurotransmitters.

\section{Acknowledgements}

We express our sincere thanks to Dr. B. N. Chandrashekar and Mr. C. C. Vishwanath research scholars Dept of industrial chemistry Kuvempu University for their constant support and suggestions.

\section{REFERENCES}

[1] R. Sandulescu, S. Mirel and R. Oprean, "The Development of Spectrophotometric Andelectroanalytical Methods for Ascorbic Acid Andacetaminophen and Their Applications in the Analysis Ofeffervescent Dosage Forms," Journal of Pharmaceutical and Biomedical Analysis, Vol. 23, No. 1, 2000, pp. 77-87. http://dx.doi.org/10.1016/S0731-7085(00)00277-6

[2] X. D. ShangGuan, H. F. Zhang and J. B. Zheng, "Electrochemical Behavior and Differential Pulse Voltammetric Determination of Paracetamol at a Carbon Ionic Liquid Electrode," Analytical Bioanalytical Chemistry, Vol. 391, No. 3, 2008, pp. 1049-1055. http://dx.doi.org/10.1007/s00216-008-2096-7

[3] I. Noviandri and R. Rakhmana, "Carbon Paste Electrode Modified with Carbon Nanotubes and Poly(3-aminophenol) for Voltammetric Determination of Paracetamol," International Journal of Electrochemical Science, Vol. 7, No. 5, 2012, pp. 4479-4487.

[4] C. Y. Li, G. Q. Zhan, Q. D. Yang and J. J. Lu, "Electrochemical Investigation of Acetaminophen with a Carbon Nano-Tube Composite Film Electrode," Bullatin of Korean Chemical Society, Vol. 27, No. 11, 2006, pp. 1854-1860.

[5] O. Gilbert, B. E. Kumara Swamy, U. Chandra and B. S. Sherigara, "Simultaneous Detection of Dopamine and Ascorbic Acid Using Polyglycine Modified Carbon Paste Electrode: A Cyclic Voltammetric Study," Journal of Electroanalytical Chemistry, Vol. 636. No. 1-2, 2009, pp. 80-85. http://dx.doi.org/10.1016/j.jelechem.2009.09.016

[6] F. N. Atta, A. Galal and S. M. Azab, "Electrochemical Determination of Paracetamol Using Gold Nanoparticles -Application in Tablets and Human Fluids," International Journal of Electrochemical Science, Vol. 6, No. 10, 2011, pp. 5082-5096. 